\title{
Languages in contact: The influence of language activation and competing language patterns on translation performance*
}

\author{
Maureen Ehrensberger-Dow (Zürich)/Susanne J. Jekat (Zürich)
}

\begin{abstract}
The two pilot studies described in this article, both part of a larger on-going project investigating multilingualism in a translation context, deal with separation of languages in translation students. At the same time, they demonstrate how multilingualism research can be integrated into the translation classroom. Within the framework of Grosjean's model (1997, 1998, 2001), the first study tests the influence on translation performance of preferentially activating one of the languages for the translation version Spanish (L2) into German (L1). The second assesses the transfer of structures from the dominant language in translating from German (L1) into English (L2). Despite the relatively small database, various inferences can be made about multilingual language processing in trainee translators.
\end{abstract}

\section{$1 \quad$ Introduction}

The issues of languages in contact and the dynamic mutual influence of source and target languages are particularly pertinent in the realm of translation education. As Neubert (2000) argues in his review of translator training, we are only beginning to grasp how complex the demands on translators' knowledge and language skills are. For example, the widespread assumption, supported by the so-called Nairobi recommendation (UNESCO 1976: 14d), that translation should be into the mother tongue of the translator or a language "of which he or she has a mastery equal to that of his or her mother tongue" does not always reflect the pragmatics of the real world. ${ }^{1}$ People often expect professional translators to be able to translate into one or more other languages (L2) in addition to their first language (L1). English is a special case in Europe, which is currently being used as a lingua franca (cf. Hoffmann 2000 and James 2000). For example, the corporate language of choice for many multi-national companies in Switzerland is increasingly English. The often unspoken expectation that

\footnotetext{
* The research reported here is part of a larger project "Research in the translation classroom" (supported by the Department of Applied Linguistics and Cultural Studies) in collaboration with Paula Bazo Castellanos, Marcel Eggler, and Chris Ricketts. We would like to express our appreciation to them for permission to use these data, as well as to the 2003/04 first- and second-year translation students at the Zurich University of Applied Sciences Winterthur for their participation and to Heather Bryn-Thomas, Martina von Arx, and Claudia Isler for their assistance in collecting the native speaker judgments.

1 Williams (1994) notes that translating and interpreting from L2 into L1 is more of a prescriptive rule than a descriptive one. See also Baker (1998) for a discussion of this issue.
} 
everyone is competent in that language places extraordinary demands on all text producers. The translation department of such companies may suddenly be confronted with having to produce an enormous quantity of high-quality English texts with translators who had previously been expected to translate into the national languages (German, French, and Italian). Although much of translation theory has been based on the tacit assumption of the mother tongue as the target language, the challenges of translation into a second or third language are different and only recently have been the subject of empirical investigation (see Campbell 1998 for a discussion with respect to English).

Not only these sociolinguistic changes, but also the recognition that separation of languages can be a problem for multilinguals (for a discussion of this phenomenon in child language see, for example, Meisel 2000) have implications for the question of which language (source or target) should be the focus in translator training.

This article presents two empirical studies of languages in contact in the field of translation education. In the first, the notion of language mode and language activation (Grosjean 1997, 1998, 2001) and its general influence on translation performance is tested with students translating from Spanish (L2) into German (L1). The second study investigates transfer from the dominant language with students translating from their L1 (German) into their L2 (English) by testing particular structures that have competing patterns in the two languages. In the following sections, the design and initial results are presented. Although the larger project is still in progress and the results of these pilot studies must be treated as preliminary, they provide promising indicators of how easily empirical research techniques can be incorporated into the translation classroom.

\section{Pre-activation of source or target language}

\subsection{Theoretical framework}

Multilingual speakers and interpreters often report that their oral performance in a particular language (even in their first language) depends partly on the language they speak immediately beforehand. A model developed by Grosjean $(1997,1998,2001)$ is based on and accounts for such observations. He uses the term "language mode" to describe the current state of activation of multilingual speakers' language systems in a particular situation and represents the various states of activation of the respective languages as a multi-dimensional system. Using the example of a bilingual speaker, he explains (2001: 3) that the degree of activation of the bilingual's languages can range from highly active to deactivated with the ensuing language mode ranging from a monolingual mode to a bilingual mode.

Grosjean clearly assumes that one of the languages, which he refers to as the base language, is the main language at a particular point in time, is subject to a higher degree of activation than any other language, and governs language processing. His designation base language relates to the current communicative situation; in another situation presumably a different language can be activated to that language mode. According to Grosjean (2001: 4), a French-English speaker talking to a monolingual French speaker would be in monolingual French mode, with English deactivated, and the converse would be true for a monolingual English communica- 
tive situation. If the same speaker met another bilingual French-English speaker and both spoke French together, switching occasionally to English, then the speaker would be in bilingual French mode, and so on.

The consequences of different language modes on the linguistic behavior of a multilingual speaker vary. According to Grosjean (2001), occurrences of code-switching (the complete switch to another language for a word, phrase, or whole sentence), borrowing (a word or short expression from the other language that is adapted morphologically and sometimes phonologically to the base or A language), and language mixing should be drastically reduced if the speaker is in monolingual mode, with the second language deactivated, although he allows that dynamic interferences might not be completely absent.

As evidence for the influence of language mode on language production, Grosjean (2001) refers to numerous studies on code-switching (e.g. Poplack 1981 and Treffers-Daller 1998). These show that speakers' positions on the language mode continuum triggers their language choice and code-switching behavior. For example, more code-switching occurs in situations when everyone understands all of the languages used.

In the area of language comprehension, Grosjean (2001) refers to a number of studies that produced related results by unintentionally manipulating variables. Grainger and Beauvillain (1987), for example, investigated language comprehension in French-English bilinguals using word lists. The lists were either monolingual (only English or only French words) or mixed (words from both languages). The bilinguals were slower in word recognition when the lists were mixed and faster when the lists were monolingual. Grosjean (2001: 10f) explains this by claiming that the bilinguals were in monolingual mode when the lists were monolingual and were able to decide faster because only one language was activated whereas in bilingual mode with the mixed list both languages were activated, thus slowing reaction times. ${ }^{2}$

Although he argues plausibly for the concept of language mode and the corresponding activation possibilities of two (or several) languages along a continuum from monolingual to bilingual mode, Grosjean (2001: 17) stresses that more empirical work must be done to establish which factors in the communicative situation affect language mode. For instance, there has been little if any investigation into the influence of various language activation constellations on translation performance. From Grosjean's (2001) model, it can be assumed that a high degree of activation would put a language in A mode. The activated language would then serve as the base language in a translation situation and presumably have a strong influence on the other language used by the translator. Initial indications of this type of influence are noted by Rossi (2003), who asked translators, among other things, about their experience with separation of languages during translation.

In order to investigate the influence of language mode on the translation process, an empirical study was designed to test whether activating the source or target language under certain

\footnotetext{
2 More recent research on word recognition in trilinguals (Dijkstra/van Hell 2003) testing Grosjean's (1997) model suggests that an interactive activation model is more appropriate than a strict language mode view.
} 
conditions can lead to differences in translations or whether such activation might even trigger negative transfer (i.e. inappropriate use of structures from the activated language in the less activated language).

\subsection{Approach}

Although the questions of what triggers negative transfer in relatively balanced bilinguals like translators and how translators manage to keep their languages separate remain to be investigated, following Grosjean $(1997,1998,2001)$ we assume here that the degree of activation of the languages involved (source and target) must play an important role. In this context, it is not at all clear whether it is better for translators to have the target language highly activated before and during the translation process (to optimally produce the target text), or the source language (to optimally understand and therefore translate the source text), or both, and in that case to what degree the two languages should be activated relative to each other. At present these phenomena are not adequately explained for trained translators or for bilinguals who are not (yet) trained translators. An ideal opportunity to test whether preferential activation of a language affects the process of translation is presented by translation classes, because it can be assumed that although students are highly competent in the languages involved, they are more subject to negative transfer between languages than trained translators. Correspondingly, a different degree of activation in one of the two languages before and during the translation process and an analysis of the resulting translations should permit some inferences to be made about the possible influence of various language activation combinations. In general for translator training, it can be said that logistical considerations, timetabling restrictions, and availability of qualified native speaker teachers may limit the choices for some programs. To our knowledge, the efficacy of the teaching language and its possible effects on the translation process has not been investigated.

During a translation lesson, one language of the pair involved (usually the target) might be preferentially activated by discussing thematic issues, potential translation problems, and difficulties (cf. Nord 1997). The other language then is presumably only truly activated once the students begin reading and translating the source text. By setting up contrasting situations in which either the source or target language is highly activated prior to translation, it should be possible to discern whether conscious activation of a language influences the translation process, an effect that, as predicted by the hypothesis presented in the previous section, should be relatively independent of whether the activated language is the student's L1 or L2.

To test the feasibility of this approach for wider application, a small pilot study was carried out in the translation version Spanish-German. ${ }^{3}$ One language (either the source or target language) was preferentially activated by a native speaker of that language in two coordinated sessions over a period of two weeks, as described in the next section.

\footnotetext{
${ }^{3}$ Unfortunately, there were not enough students in the second-year German-Spanish translation class to justify running the pilot study in both versions. The larger project now in progress includes a different language pair, both translation directions, and more groups of students.
} 


\subsection{Experimental Design}

\subsubsection{Participants}

In this pilot study, 12 students in their second year of translation studies in Switzerland with German as their native language (G L1) and Spanish as a second language (Sp L2) took part, as well as a native German-speaking teacher with good knowledge of Spanish and a native Spanish-speaking teacher with good knowledge of German. The students knew both teachers and their respective language backgrounds.

\subsubsection{Pre-activation of the target language (session 1)}

The testing took place in two sessions of a triple-hour lesson one week apart. In the first session, the German (G L1) students translating from Spanish (Sp L2) had their German highly activated by their native German teacher prior to a translation task. Referring to a recent related newspaper article in German that the students had in front of them and key figures and statistics on the topic of the source text, he led a discussion and encouraged the students to participate actively in the first 45 minutes of the triple-hour class. The language of choice during the 10-minute break was also German. In the 90 minutes following the break, the students translated the first extract of a Spanish text into German.

\subsubsection{Pre-activation of the source language (session 2)}

In the following week, the class had a guest lecture from a native Spanish teacher before they did any translation work. Similar to what the German teacher had done with the class in the previous week, she activated Spanish by highlighting relevant vocabulary and discussing a Spanish parallel text related to the newspaper article of the previous week. Again, the students were encouraged to participate as actively as possible in the first 45 minutes of the class, thus highly activating their Spanish. During the 10-minute break, the teacher engaged the students in conversation, still in Spanish. In the remaining 90 minutes of the lesson, the students translated the second extract of the same Spanish text into German, again with their German teacher present.

\subsubsection{Stimuli}

Both translation tasks were based on extracts of approximately the same number of words (270) of the same text (an objective report of approximately 1600 words) on the same topic (the spread of HIV and AIDS; Ministerio de Sanidad y Consumo, 2001). The choice of text and extracts was dictated by a number of factors: appropriate level of difficulty for secondyear students and comparability with respect to vocabulary, content, and language register; availability of comparable Spanish and German parallel texts for the activation phase; cohesion and coherence of the extracts in isolation; and reasonable length for completion during class time.

\subsubsection{Procedure and evaluation method}


At the beginning of the experiment, the students were informed by their German teacher that he and his Spanish colleague would be collecting some data for research purposes. No theoretical background or details were provided.

The translations were collected at the end of each session, copies were made and retained, and no feedback was given until after both sessions were over. At the end of the second session, the students were asked for their intuitions as to any differences in their translating when they were first active in the source language or the target language. Subsequently, the translations were read by the teacher and returned to the students with comments and corrections. At this point, the students were asked for their permission to use the copied translations for the present study. All translations were treated anonymously, with codes replacing the students' names.

For the pilot study presented here, the performance of two randomly chosen students was compared over the two sessions (activation of the target language German in the first session and activation of the source language Spanish in the second session) by analyzing their translations. Error categories comprised 11 types of sentence-level errors (e.g. lexical, morphological, syntax, formal), 5 types of text-level errors (e.g. content, logic), and 4 types of translation errors (e.g. semantic discrepancies between the source and target text). ${ }^{4}$

\subsection{Preliminary results}

In terms of the students' subjective evaluation of the translation task, the activation of the target language in the first session seemed to have had a different effect from the activation of the source text in the second session, although both source text extracts were from same text (Ministerio de Sanidad y Consumo, 2001). Informal feedback from the 12 participants was practically unanimous that the text extract from the first session (activation of the target language) was more difficult to translate than the extract from the second (activation of the source language).

This subjective impression of the participants was confirmed by the performance of the two students whose translations were examined in greater detail (Stud1 and Stud2; see Table 1).

\footnotetext{
${ }^{4}$ For the purposes of this pilot study, the analysis categories are not discussed in depth. It is possible that they have to be expanded upon in the larger project.
} 
The influence of language activation and competing language patterns on translation performance

Table 1. Number of errors in two students' translations by activation condition

\begin{tabular}{l|c|c|c|}
\cline { 2 - 4 } \multicolumn{1}{c|}{ Stud1 } & $\begin{array}{c}\text { Sentence-level } \\
\text { errors }\end{array}$ & $\begin{array}{c}\text { Text-level } \\
\text { errors }\end{array}$ & $\begin{array}{c}\text { Translation } \\
\text { errors }\end{array}$ \\
\hline Activation of target language (G L1) & 10 & 4 & 4 \\
\hline Activation of source language (Sp L2) & 8 & 1 & 2 \\
\hline Stud2 & & & 2 \\
\hline Activation of target language (G L1) & 11 & 3 & 3 \\
\hline Activation of source language (Sp L2) & 6 & 2 & \\
\hline
\end{tabular}

Whereas the translations from the first session (activation of the target language German) had a total of 18 and 16 errors for both Stud1 and Stud2, those from the second session (activation of the source language Spanish) had only 11 each. The difference in performance was also qualitative, in that it was due to a reduction in sentence- and text-level errors, not translation errors. It is not immediately obvious why activation of the source language should lead to fewer errors in the target text.

On the basis of the initial analysis, some conjectures can be made about the effects of the different language activation. It is possible that activation of the source language improved reading comprehension, since Stud1's second translation had fewer errors related to the topic of the text and Stud2's had fewer related to the logic (text-level errors). The quantitative analysis also suggests a correlation between the differences in translation performance with various degrees of language activation (improvement in the overall performance of the source language, L2, with native speakers of the target language, L1). Such a result could correspond to the hypotheses extrapolated from Grosjean $(1997,1998,2001)$.

Since Stud1 and Stud2 were both native speakers of the target language, activation of the source language (their L2) might weaken any latent activation of their L1 to the benefit of their L2, resulting in improved understanding of the source text. At the same time, it can be assumed that the relative dominance of German as L1 hinders negative transfer from the L2 Spanish (also see Edmondson/House 2000). The present results have to be interpreted with caution because of the very real possibility that increased familiarity with the topic and knowledge of the first text extract led to improved translation performance in the second session. ${ }^{5}$

Only a detailed analysis of all the translations and evaluation of the errors with respect to negative transfer between L1 and L2 considering the language constellations of the individual participants can confirm or refute these preliminary findings. Nevertheless, the present pilot study has allowed some insight into the issue of language contact for multilinguals.

The preliminary results for the effect of activation of the source language prior to a translation task are promising and, if confirmed by the larger project, have important implications for

\footnotetext{
${ }^{5}$ In the larger project, a sufficient number of groups are included to counter the potential confound of activation condition with order of presentation.
} 
translation training. Among other issues to be investigated empirically are the differences between the effects of source and target language activation, depending on whether they are the L1 or L2 of the respective multilinguals. For example, the dominance of L1 might detrimentally influence the choice among competing translation variants of particular structures. The following section presents a study concerned with translation into L2 and the effect of L1 language patterns that compete with those of L2.

\section{The influence of competing language patterns in $\mathrm{L} 2$ translation}

\subsection{Theoretical framework}

The issue of language contact may be accentuated with translation into a second language since presumably L1 language structures compete as tempting but sometimes inappropriate alternatives to L2 structures. Herdina and Jessner (2002) refer to "cross-linguistic interaction" to explain the dynamic aspect of a multilingual system but make no claims as to its effects on translation performance. Campbell (2000) argues that it may be difficult for translators to avoid L2 grammatical forms and lexis that they are not completely confident about because in translation tasks the propositional content is already given, thus possibly restricting syntactic and lexical choices. With respect to the language pair German-English, we have identified a number of problem areas in the written English of our L2 language students in previous research (Ehrensberger-Dow/Ricketts 2003). Although even our first year translation students are highly competent in English and may be aware of L2 grammatical rules at the sentence level, they may simply lack the experience to judge which form is appropriate since much of natural usage is pragmatically and contextually driven.

Another possibility is that our students are influenced by their exposure to less-than-nativelike English in their education. Not only the world of business but also the realm of academe has been affected by the widespread acceptance of English as the global language of science and Anglo-Saxon text conventions as the standard for scientific writing. For instance, few other languages have a tradition of such things as an "abstract" yet academics are expected to be able to produce these (or have translators do so) if they want to be considered for publication in professional journals or participation in academic conferences. These texts in turn become part of the discourse community and serve as models of high register, academic English.

Native-speaker teachers are often confronted with comments to the effect of "But I've always said it that way!" or "But I've heard (seen) that lots of times!" when an error or unnatural structure is pointed out to them. In a country like Switzerland, where English has become the language of choice for many companies and is in obvious evidence on billboards and in print headlines and advertisements, it is hardly surprising that patterns more closely associated with the language of the region (in our case, German) have emerged in English (cf. Baumgarten et al. 2001, for the translation version English-German). Presumably native speakers (including teachers and professional translators) living outside of their language communities are also influenced by exposure to the non-native English around them and may begin to accept and even produce otherwise non-standard forms and structures (see Porte 2003 for a discussion of 
EFL teachers in Spain, and for an overview of languages in contact, see Thomason 2001 or Baker/Prys Jones 1998).

For the languages German and English, which are closely related at various levels, it can be assumed that frequently-occurring structures in one language might represent possible but unusual patterns in the other. The direct transfer of the former structures during the translation process therefore might result in texts that are perceived as unnatural by English L1 target readers. This phenomenon is investigated in the following pilot study.

\subsection{Approach}

To ensure that the English expected of non-native student translators actually corresponds to the English produced by native speakers, translation teachers can access good-quality comparable texts that have been published in print or made available on the internet. The presence of certain syntactic structures, collocations, etc. in such texts provide support that usage is appropriate for that particular text type and genre. In the case of individual language features, however, it cannot be assumed that the absence of a form in comparable texts means that the form would not be an acceptable variant. Only if all imaginable variants of sentences with the same propositional content were evaluated by a sufficient number of native speakers, could a non-native speaker be confident that choosing the preferred variant(s) would result in acceptable, natural language. Although grammars based on corpus research (e.g. Biber et al. 1999) have made substantial contributions to addressing the question of what "real" English is, they are ultimately only a description of what forms are most frequently used in what contexts and not what native speakers know can be used (cf. Newmeyer 2003). As such, they may be of limited aid to translators of complex, high-level texts.

Since German sentences with adverbials are often translated into distinctly unnatural or incorrect English by our students, we decided to examine this area of L2 translation more closely. The use of English adverbials may be a problem in and of itself, but there may also be a lack of awareness of how German adverbial information can be conveyed in English. Discourse functions and the semantics of certain types of German adverbials can be realized in various ways in English, many of which are not exploited by novice translators, perhaps because of an over-reliance on word-for-word translation. Even when an English adverbial might provide an appropriate translation for a German adverbial, its order with respect to the other words in the sentence can be problematic for non-native speakers. A structure that might sound fine when back-translated into German may be highly marked, if not unacceptable, in English. It may be only when the two languages are in direct contact (i.e. during the translation process) that such subtle differences become a problem and only in the translation context can they be addressed (i.e. during translation training).

In the following, part of a study investigating the effectiveness of focused grammar instruction in translation training (Ricketts/Ehrensberger-Dow, in preparation) is described in which translations from trainee translators are examined to determine the degree of negative transfer from the source language and whether this transfer would be considered acceptable or not by native speakers. 


\subsection{Experimental Design}

\subsubsection{Participants}

A total of 34 students (L1 German, L2 English) in their first-year of translation studies in Switzerland participated in the study. In addition, 20 adult native speakers of English (10 living in Canada and 10 living in England) were asked to provide acceptability judgments for variants of English sentences.

\subsubsection{Test items}

Of particular interest for this study was how the students dealt with common German structures that are normally realized quite differently in English. The adverbs schon and bereits are two such cases: both can be translated with "already" or "even" or left out if the time reference is otherwise clear (with time adverbials or verb tense and/or aspect). ${ }^{6}$ In addition, schon can be used as an intensifier, with various possible translations, including omission (see Pons Collins 1997). Some structures in English similar to German may be grammatically possible, but unusual or of questionable acceptability to native speakers (for example, the position and presence of the word "already" in: "Already the Luther bible heavily influenced the development of modern German.").

Five sentences with these German adverbs were included in a larger test set of 15 isolated German sentences with a variety of adverbials. Two of the five sentences of interest might have seemed quite familiar to the students whereas the other three had probably never been encountered before (see Appendix A for the list). The 15 German test set sentences were checked independently and judged to sound natural by two linguistically sophisticated native speakers of standard German (both university professors). The order of the sentences was randomized for presentation.

For each of the 15 test sentences, four possible English translations were devised (see Appendix A). One variant was as close as possible to a word-for-word translation, within the syntactic and lexical constraints of English. One or two other variants were the preferred translation(s) for the German-English translation teacher and any others were grammatically permitted variants with as many of the same lexical items as possible. The four variants were randomly ordered within each item.

\subsubsection{Procedure and evaluation method}

The translation students received the randomized set of German sentences as a pre-test at the beginning of their $1^{\text {st }}$ semester to provide a baseline of errors for a separate study involving the translation of certain types of German adverbials into English. During class time and as a normal class exercise, they were asked to take about 20 minutes to write an English transla-

\footnotetext{
${ }^{6}$ Regardless of potential translation difficulties, the usage of "already" and "even" is obviously problematic for all learners of English, as evidenced by the extended explanations devoted to these points in reference works (e.g. Swan 1995, Collins Cobuild 1990).
} 
tion for each of the 15 German sentences. All managed the task easily, with only a small number of items left incomplete or blank.

Parallel to collecting data from student translators, we had English native speakers judge the 4 possible English variants for each of the pre-test sentences as to their acceptability by marking them with codes for their judgments, as shown in Table 2.

Table 2. Codes for the acceptability judgments from English native speakers

\begin{tabular}{|c|l|}
\hline Code & Judgment \\
\hline $\mathrm{X}$ & This sentence sounds unnatural and incorrect. I'd never use it. \\
\hline$?$ & This sentence sounds ok but not very natural. I don't think I'd use it myself. \\
\hline$\sqrt{ }$ & This sentence sounds natural and correct. I'd probably use it myself. \\
\hline$\sqrt{ } \sqrt{ }$ & This is definitely my favorite! \\
\hline
\end{tabular}

The native speakers were not told that the variants were translations, but were merely asked to indicate their reactions to each. They did not have to make a forced choice: they were free to use the same code for more than one variant in each set of four if they wanted.

\subsection{Preliminary results}

The pattern of choices for the two groups of native speakers (Canadian and English) was virtually identical for the five items of interest, so the results were combined. Although the acceptability judgments were not forced choice (i.e. any and all four acceptability judgments were available for the four variants of each item), one variant in four of the five items of interest received a majority of $\sqrt{ } \sqrt{ }$ ratings (between 14 and 18 of the 20 responses). Combining the two most acceptable variants (with codes of $\sqrt{ } \sqrt{ }$ and $\sqrt{ }$ ) yielded preferred variants for each item (two items only had one preferred variant, three items had two preferred variants). These contrast in each item with a single variant most often judged unnatural (coded X). The degree of agreement among the native speakers for the most and least favorite variants was very high (94\% and 86\%, respectively): apparently they knew and agreed which variants they preferred and which they did not. Although the category of questionable (?) acceptability was available, it was not used very often; the seven sentences that were not clearly preferred or judged unacceptable received mixed ratings and can therefore be thought of as questionable variants. The results for all categories are presented in Table 3. 
Table 3. Average percentage of agreement in native speaker judgments

\begin{tabular}{|l|c|c|c|}
\hline Acceptability judgments (20 speakers judging 20 sentences) & $\sqrt{ } \sqrt{ } \sqrt{ }$ & $?$ & $\mathrm{X}$ \\
\hline Preferred variants (8 sentences) & 94 & 5 & 1 \\
\hline Questionable variants (7 sentences) & 19 & 37 & 44 \\
\hline Unacceptable variants (5 sentences) & 1 & 13 & 86 \\
\hline
\end{tabular}

On analogy to grading systems, letters were assigned to each of the variants based on the native speakers' judgments and used as a measure to assess the students' translations (see the Appendix). For possibilities not included in the choices presented to the native speakers, the grade $\mathrm{C}$ was assigned for an acceptable translation (grammatically correct, relatively natural), and $\mathrm{E}$ indicated an unacceptable translation (grammatically incorrect and/or a mistranslation). In fact, the latter two categories were used quite often because, contrary to expectations, the students produced acceptable variants other than the ones tested with the native speakers and a large number of unacceptable translations (see Table 4).

Table 4. Percentage for each grade for students' translations (34 translations of 5 sentences)

\begin{tabular}{|l|r|}
\hline Grade & Percentage \\
\hline A/B (variants preferred by native speakers) & 22 \\
\hline C (other acceptable variant) & 14 \\
\hline D (questionable variants for native speakers) & 25 \\
\hline E (other unacceptable variant) & 35 \\
\hline F (variant judged unacceptable by native speakers) & 4 \\
\hline
\end{tabular}

Clearly these structures were problematic for our students: only about one-third of the translations were acceptable (36\%, total of A/B and C) and even more were unacceptable (39\%, total of $\mathrm{E}$ and $\mathrm{F}$ ). It is easy to attribute this latter group of poor translations to a lack of experience or language competence on the part of these beginning students, things translation educators are accustomed to dealing with.

For the present discussion, the most interesting category is D, variants which native speakers found questionable and claim not to produce, yet account for $25 \%$ of our students' responses. A closer examination of the grades associated with the individual items lends some insight into what might be happening. The two German sentences that were probably familiar (numbered 13 and 14, Appendix A) were quite successfully translated, with more than half of the translations considered acceptable (i.e. assigned grades of A, B, or C). The students may well have been exposed to preferred English variants of these or similar sentences previously. In fact, a quick text check with an internet search engine like Google produces thousands of hits for the preferred English versions. The relatively good results for these two sentences probably reflect what Campbell (1998:17) refers to as a translators' strategy of having "formulaic utterances, prefabricated routines and prefabricated patterns" easily accessible.

By contrast, English variants of the other three sentences had probably never been encountered before and the students had to rely on whatever resources they had available, including the patterns of their L1. The variants graded D were twice as frequent as the A/B and C 
variants combined for these three sentences (32\% vs. 15\%). These questionable variants produced by our first-year translation students are grammatically possible but presumably occur seldom, if ever, in the English of native speakers that they are exposed to. Rather than attempting to make analogies to patterns of natural English they knew, our students seemed to have been overly influenced by their L1 patterns. If such translations were proofread by professional editors, they would probably be revised to more acceptable variants. However, since native speakers did not clearly reject these, they might be accepted as reasonable, especially if proofread by non-native speakers with the same L1 as the translators. The issue for the dynamic process of languages in contact is how many times such questionable variants need to be used (in print or otherwise) before they become acceptable and part of the local language. The questionable variants may represent the gray zone of language change.

Avoiding such L1-influenced forms in L2 translations drives much of the translator training provided by native speakers. Rather than merely accepting such questionable variants as correct or rejecting them as unacceptable, teachers might do better to draw these to their students' attention to heighten their awareness of what influences other languages, especially their L1, might be having on the translation process. The production of questionable variants, in this light, can be considered not only evidence of languages in contact, but perhaps an opportunity to help our students in the search for that elusive "natural" English they will be expected to produce as professionals. A method that is currently being assessed in first-year German-English translation classes at our institution is grammar instruction focused specifically on these types of cross-linguistic conflicts.

\section{Discussion}

The empirical results from both pilot studies reported here suggest that our understanding of languages in contact must extend to the individual users of those languages and the multilingual situation at hand. A greater appreciation of the variables involved in contact situations would have important implications in a number of areas, including translation education.

The results from the activation study based on Grosjean's (2001) model imply that multilinguals can optimize their performance, at least in translation tasks, by preferential activation of one of their languages. Further research should help clarify what role L1 and L2 have with respect to source and target language and could motivate curriculum design for translation teaching. Perhaps students should learn to activate the source language (by discussing the text, doing text analysis, etc.) before attempting translation.

The second study confirmed that inappropriate patterns from the source language can be transferred into the target language, at least when the latter is the students' L2. That this influence was found in translations into English, currently assumed to be the lingua franca in Europe, suggests that its sociolinguistic dominance has little to do with dominant language influence in our multilinguals. Whether those patterns would also appear in spontaneous L2 productions of the same students is another question that must be investigated further. Certainly more research needs to be done into the source of such influence in order to develop methods to deal with it. Only through heightened understanding of the mutual influences of 
languages in contact on the part of both educators and students can education and translation performance be improved.

The issue remaining to be addressed in the larger project that these pilot studies form part of is how to best deal with the various translation directions (L2 into L1 and/or L1 into L2) with respect to the problem of language separation. This also concerns the presumed special position of English for translation students.

\section{References}

Baker, Colin/Prys Jones, Silvia (1998): Encyclopedia of Bilingualism and Bilingual Education. Clevedon.

Baker, Mona (1998): Routledge Encyclopedia of Translation Studies. London.

Baumgarten, Nicole/House, Juliane/Probst, Julia (2001): "Untersuchungen zum Englischen als lingua franca in verdeckter Übersetzung. Theoretischer Hintergrund, Weiterentwicklung und erste Ergebnisse." Working Papers on Multilingualism 20: SFB 538.

Biber, Douglas/Johansson, Stig/Leech, Geoffrey /Conrad, Susan/Finegan, Edward (1999): Longman Grammar of Spoken and Written English. Harlow.

Campbell, Stuart (1998): Translation into the Second Language. New York.

Campbell, Stuart (2000): "Critical structures in the evaluation of translations from Arabic into English as a second language". The Translator 6: 211-29.

Collins Cobuild (1990): Collins Cobuild English Grammar. London.

Dijkstra, Ton/van Hell, Janet G. (2003): "Testing the language mode hypothesis using trilinguals". International Journal of Bilingual Education and Bilingualism 6(1): 2-16.

Edmondson Willis/House,Juliane ( $\left.{ }^{2} 2000\right)$ : Einführung in die Sprachlehrforschung. Tübingen/Basel.

Ehrensberger-Dow, Maureen/Ricketts, Chris (2003): "What's wrong with our Swiss students' English? An analysis of advanced learners' written productions". Bulletin Suisse de linguistique appliquée 77: 103-121.

Grainger, Jonathan/Beauvillain, Cecile (1987): "Language blocking and lexical access in bilinguals". Quarterly Journal of Experimental Psychology 39A: 295-319.

Grosjean, François (1997): "The bilingual individual". Interpreting 2(1/2): 163-187.

Grosjean, François (1998): "Studying bilinguals: Methodological and conceptual issues". Bilingualism: Language and Cognition 1: 131-149.

Grosjean, François (2001): "The bilingual's language modes". In: Nicol, Janet L. (ed.): One mind, two languages: bilingual language processing. Malden, Mass.: 1-22.

Herdina, Philip/Jessner, Ulrike (2002): A Dynamic Model of Multilingualism. Clevedon.

Hoffmann, Charlotte (2000): "The spread of English and the growth of multilingualism with English in Europe". In: Cenoz, Jasone/Jessner, Ulrike (eds.): English in Europe. The Acquisition of a Third Language. Clevedon: 1-21.

James, Allan R. (2000): "English as a European lingua franca. Current realities and existing dichotomies". In: Cenoz, Jasone/Jessner, Ulrike (eds.): English in Europe. The Acquisition of a Third Language. Clevedon: 22-37. 
The influence of language activation and competing language patterns on translation performance

Meisel, Jürgen M. (2000): "The simultaneous acquisition of two first languages". Working Papers on Multilingualism 7: SFB 538.

Ministerio de Sanidad y Consumo (2001): Plan de Movilización Multisectorial 2001-2005. [Der Link ist mittlerweile nicht mehr verfügbar].

Neubert, Albrecht (2000): "Theory and practice of translation studies revisited. 25 years of translator training in Europe". In: Beeby, Allison/Ensinger, Doris/Presas, Marisa (eds.): Investigating Translation. Selected Papers from the $4^{\text {th }}$ International Congress on Translation, Barcelona, 1998. Amsterdam: John Benjamins: 13-26.

Newmeyer, Frederick (2003): "Grammar is grammar and usage is usage". Language 79: 682707.

Nord, Christiane (1997): Translating as a Purposeful Activity. Functionalist Approaches Explained. Manchester.

Pons Collins (1997): Collins German-English English-German Dictionary. Unabridged. Glasgow.

Poplack, Shana (1981): "Syntactic structure and social function of code-switching". In: Durán, Richard P. (ed.): Latino language and communicative behavior. Norwood, New Jersey.

Porte, Graeme (2003): "English from a distance: Code-mixing and blending in the L1 output of long-term resident overseas EFL teachers". In: Cook, Vivian (ed.): Effects of the Second Language on the First. Clevedon.

Ricketts, Chris/Ehrensberger-Dow Maureen (in preparation): "Assessing the impact of explicit grammar instruction on translation into English". Zurich University of Applied Sciences Winterthur.

Rossi, Alessandra (2003): Spracherwerbssituation im Zusammenhang mit der Übersetzerausbildung ("Language acquisition patterns with respect to translator training"). BA thesis, Zurich University of Applied Sciences Winterthur.

Swan, Michael (1995): Practical English Usage. Oxford.

Thomason, Sarah (2001): Language Contact: An Introduction. Washington, DC.

Treffers-Daller, Jeanine (1998): "Variability in code-switching styles: Turkish-German codeswitching patterns". In: Jacobsen, R. (ed.): Code-Switching Worldwide. Berlin.

UNESCO (1976): Nairobi Recommendation on the Legal Protection of Translators and Translations and the Practical Means to Improve the Status of Translators. http://www.ceatl.org/stddocs/nairobieng.rtf, last visited 4.02.04.

Williams, Sarah (1994): The application of SLA research to interpreting. Ms., Stockholm University. 


\section{Appendix A}

German sentences translated by students and English variants judged by native English speakers (numbers refer to order in complete list of 15 sentences; letters refers to native speaker preference for each variant)

$\mathrm{A} / \mathrm{B}=$ variants preferred by native speakers

$\mathrm{D}=$ questionable variants for native speakers

$\mathrm{F}=$ variant judged unacceptable by native speakers

4 Schon als Kind wusste er, dass er Tierarzt werden wollte.

He already knew that he wanted to become a vet when he was a child.

$\mathrm{D}$

Even as a child, he knew he wanted to become a vet.

$\mathrm{A} / \mathrm{B}$

Already as a child, he knew he wanted to become a vet.

$\mathrm{D}$

When he was a child already, he knew he wanted to become a vet.

$\mathrm{F}$

5 Er ist bereits vor zwei Stunden angekommen.

He already arrived two hours ago.

$\mathrm{D}$

He arrived two hours ago.

$\mathrm{A} / \mathrm{B}$

He arrived two hours ago already.

$\mathrm{D}$

He arrived already two hours ago.

$\mathrm{F}$

8 Er begann bereits in der Schule, harte Drogen zu konsumieren.

He began taking hard drugs when he was still at school. $\quad$ A/B

He already began taking hard drugs when he was at school. $\quad$ D

He was already taking hard drugs when he was at school. $\quad$ A/B

$\begin{array}{ll}\text { Already at school he began taking hard drugs. } & \mathrm{F}\end{array}$

13 Warst du schon in New York?

Have you ever been to New York City? A/B

Were you ever in New York City? A/B

Were you already in New York City? D

Have you been ever to New York City? F

14 Danke - ich werde schon bedient.

Thank you - I'm already served.

Thank you - I'm being already served. $F$

Thank you - I'm already being served. $\quad$ A/B

Thank you - I'm being served. A/B 